\title{
Isolated „Tillaux“ fracture in adulthood: rarity where the key of success is not to miss it
}

\author{
Gasparova $\mathrm{M}^{1,2}$, El Falougy $\mathrm{H}^{2}$, Kubikova $\mathrm{E}^{2}$, Almasi $\mathrm{J}^{1}$ \\ Orthopedic Department, District Hospital Dunajska Streda, Slovakia. gaspimari@gmail.com
}

\begin{abstract}
BACKGROUND: Fracture of the lateral border of the distal tibia is often referred as Tillaux fracture. It is an avulsion fracture due to the tension of the anteroinferior portion of the anterior tibiofibular ligament (1). This type of fracture is scarce in adulthood and can be easily overlooked.

METHODS: From 2006 to the present day, 7 case reports describing the Tillaux fracture were found in the PubMed and Web of Science database, to which one case from our set of patients was added. Our goal was to focus on the diagnostic and a selected treatment described in each published case.

RESULTS: We found no gender difference. The injury mechanism was mostly an external rotation. Treatment and diagnosis were, in all cases differentiated at specific points. Fixation and load reduction were indicated at least for six weeks in all of the patients. After three months, in almost all cases, a return to full function was achieved.

CONCLUSION: Our assessments are not statistically significant, but our goal was to point out the existence of such a rare type of fracture. At the same time, based on previous publications, we developed an algorithm of diagnosis and treatment to facilitate the management of this type of fracture (Tab. 1, Fig. 5, Scheme 1, Ref. 21). Text in PDF www.elis.sk

KEYWORDS: Tillaux fracture, distal tibia, oblique projection, osteosynthesis, external rotation.
\end{abstract}

\section{Introduction}

Paul Jules Tillaux was a French anatomist and surgeon, who lived in the 19th century and was practicing in Paris (2). He, among other things, found out from the biomechanical experiments of the rotational mechanism of injury that the anterior tibiofibular ligament remains intact and the anteroinferior part of the distal tibia disrupts (3). The most common mechanism of injury, according to observations and reports of patients, is the external rotation of the foot against the leg (4). External rotation and the resulting force cause a pull of the anterior inferior talofibular ligament on its distal tibial attachment and results in an avulsion of the lateral and distal part of the bone (2). In the vast majority of cases, this type of injury occurs mainly in children and adolescents (Salter-Harristype III), but in sporadic cases it may also occur in adults, when it is called as adult Tillaux fracture (type $\mathrm{A}$ - without ligamentous damage, type B - with associated ligamentous injury) (5). It is also necessary to point on the variability of the name of this fracture. One can find synonyms such as: adult Tillaux-Chaput fracture or Chaput tubercle fracture.

${ }^{1}$ Orthopedic Department, District Hospital Dunajska Streda, Slovakia, and ${ }^{2}$ Institute of Anatomy, Faculty of Medicine, Comenius University in Bratislava, Slovakia

Address of correspondence: M. Gasparova, MD, Orthopaedic Department, Hospital Dunajska Streda, Velkoblahovska 23, SK-929 01 Dunajska Streda, Slovakia.

Phone: +421.31.5571442
From the perspective of clinical anatomy, the distalo-lateral part of the tibia has a triangular portion oriented laterally for connection with the fibula. There is a process on the lower part of this area, which is an attachment for interosseous ligament and forms a part of the tibiofibular syndesmosis. In adulthood, this ligament is more prone to rupture than in childhood. The rupture of the ligament exhausts the force of the injury; consequently, it does not reach the bone and thus reduces fracture. In childhood, the opposite is true, ligaments are very strong, subject to the exerted force of acting as bones, and fracture types such as Tillaux fracture are more prevalent. In addition to the rare occurrence in adulthood, another feature of this fracture is that they are challenging to detect. The injury may be misdiagnosed as a sprain unless a radiographic investigation of the ankle is done (6) (7). However, it is often almost unrecognizable on standard X-ray projections (Figs 1 and 2).

\section{Materials and methods}

From the PubMed and Web of Science database and our resources, we found seven published case reports from 2006 to the present day regarding isolated Tillaux fractures in adults, to which we have, added yet unpublished case from the set of our patients. We found another study describing 19 cases of mainly isolated Tillaux fracture, but this study was focused mainly on the arthroscopic assisted treatment of this injury and also included children and not just the isolated type of Tillaux fracture. That is why we did not include this study into our group, although we would like to mention the excellent results of the arthroscopically assisted fixa- 


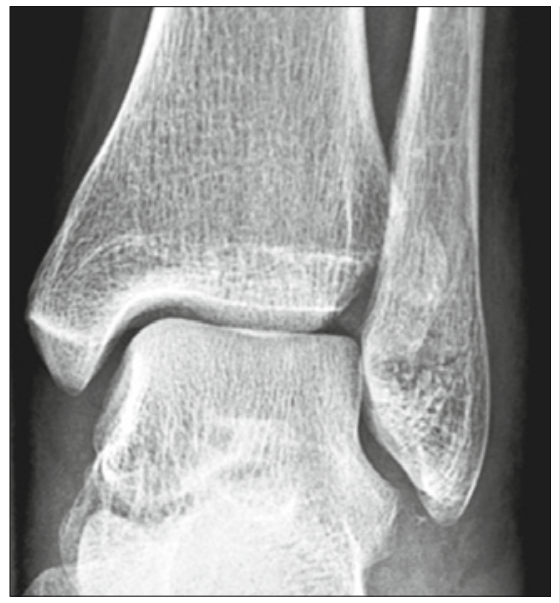

Fig. 1. "Invisible" Tillaux fracture.

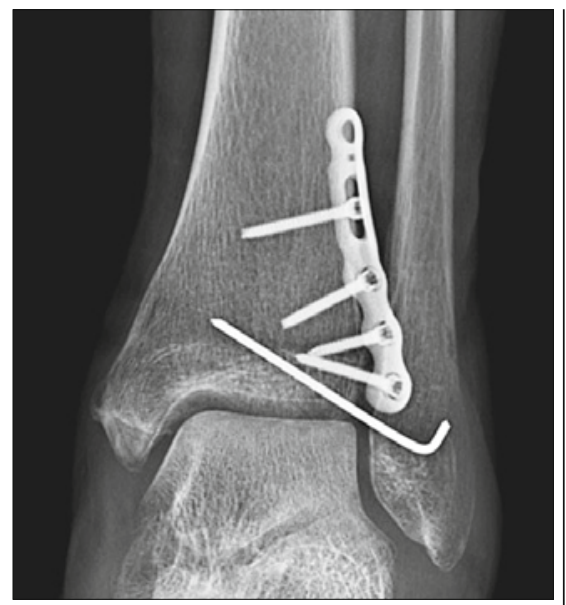

Fig. 4. Comminuted Tillaux fracture fixation with plate osteosynthesis and additional $K$ wire.

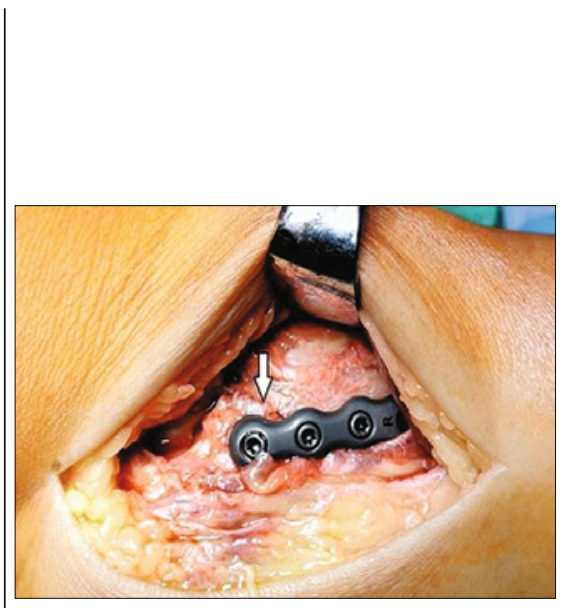

Fig. 5. Intraoperative picture, arrows point on the fracture line.

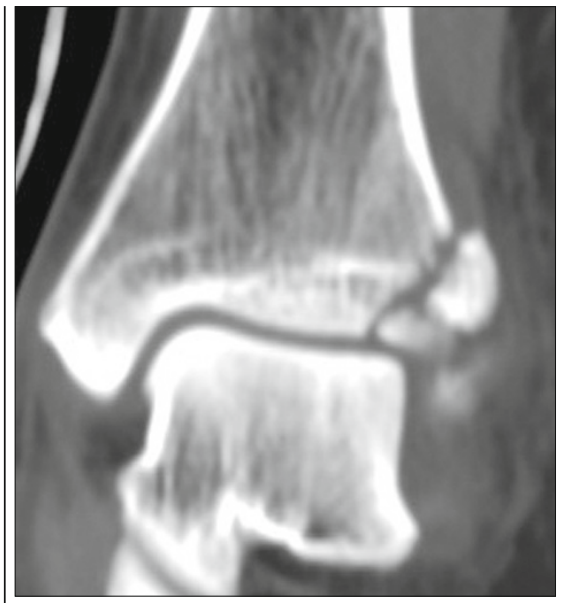

Fig. 2. The same fracture as in Fig. 1 on CT scan.

(1)

tion of the fracture (8). In the publications, we focused on specific characteristics, which we summarized in tables. These included patients`age and sex, trauma mechanism and fracture type, diagnostic methods, treatment, and patients outcomes (Tab. 1).

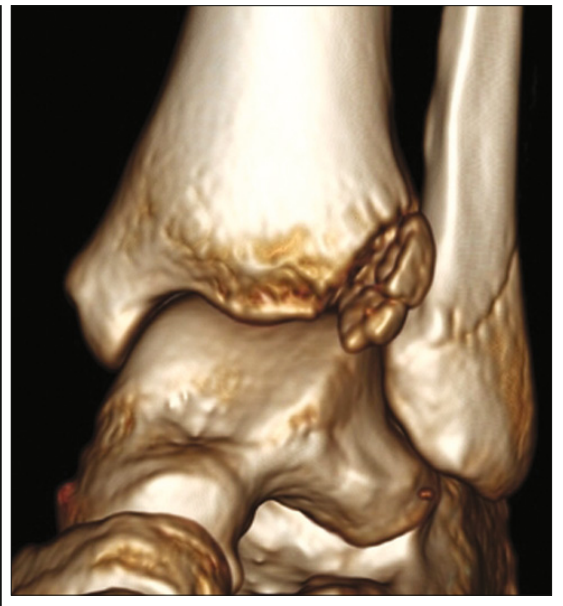

Fig. 3. 3D CT scan.

\section{Results}

By summarizing the case reports published so far, several values were evaluated, which were not statistically significant, but on the other hand, useful in the clinical practice. The average age of patients was 36.75 years, with a maximum of 60 and a minimum of 27 years. External rotation was identified as the most common mechanism of injury. From the view of clinical symptoms, mild swelling and tenderness in the distal anterolateral portion of the tibia were usually present, while mobility was mostly not limited. Gender dominance in this type of injury has not been confirmed so far. Radiologically, in addition to standard PA and lateral projections, in some cases, the stress X-ray, CT imaging and oblique projection were used as a diagnostic supplement (Fig. 3). However, there was no consensus between the individual cases that the complementary radio-diagnostic examination was most

Tab. 1. Summary of presented case studies.

\begin{tabular}{|c|c|c|c|c|c|c|c|c|c|}
\hline $\begin{array}{l}\text { Patient } \\
\text { No. }\end{array}$ & Age & Sex & $\begin{array}{l}\text { Injury mechanism: } \\
\text { External rotation }\end{array}$ & $\begin{array}{l}\text { Injury Mechanism: } \\
\text { Fall from Height }\end{array}$ & CT performed & $\begin{array}{c}\text { Fragment } \\
\text { Dislocation }\end{array}$ & $\begin{array}{l}\text { Operative } \\
\text { Treatment }\end{array}$ & $\begin{array}{l}\text { Fixation } \\
\text { In weeks }\end{array}$ & $\begin{array}{c}\text { Full recovery } \\
\text { In weeks }\end{array}$ \\
\hline 1 & 31 & $\mathrm{~F}$ & + & & & & & 6-NWB & \\
\hline 2 & 47 & $\mathrm{~F}$ & + & & + & + & + & 6 & 12 \\
\hline 3 & 37 & $\mathrm{~F}$ & + & & + & & & & 12 \\
\hline 4 & 60 & M & & + & & + & + & 6-NWB & 12 \\
\hline 5 & 27 & M & & & & + & + & 6-NWB & 12 \\
\hline 6 & 28 & $\mathrm{M}$ & & + & + & + & + & 8-NWB & 12 \\
\hline 7 & 31 & $\mathrm{~F}$ & + & & + & + & + & 6-NWB & 12 \\
\hline 8 & 33 & M & + & & + & + & + & 6-NWB + 4 WB & 10 \\
\hline Summary & $\begin{array}{c}\text { Avg } \\
36,75\end{array}$ & $\begin{array}{c}\text { Ratio } \\
1: 1\end{array}$ & 5 cases & 2 cases & 5 cases & 6 cases & 6 cases & & Avg 11,7 \\
\hline
\end{tabular}

F - female, M - male, CT - computed tomography, NWB - non-weight bearing, WB - weight bearing 


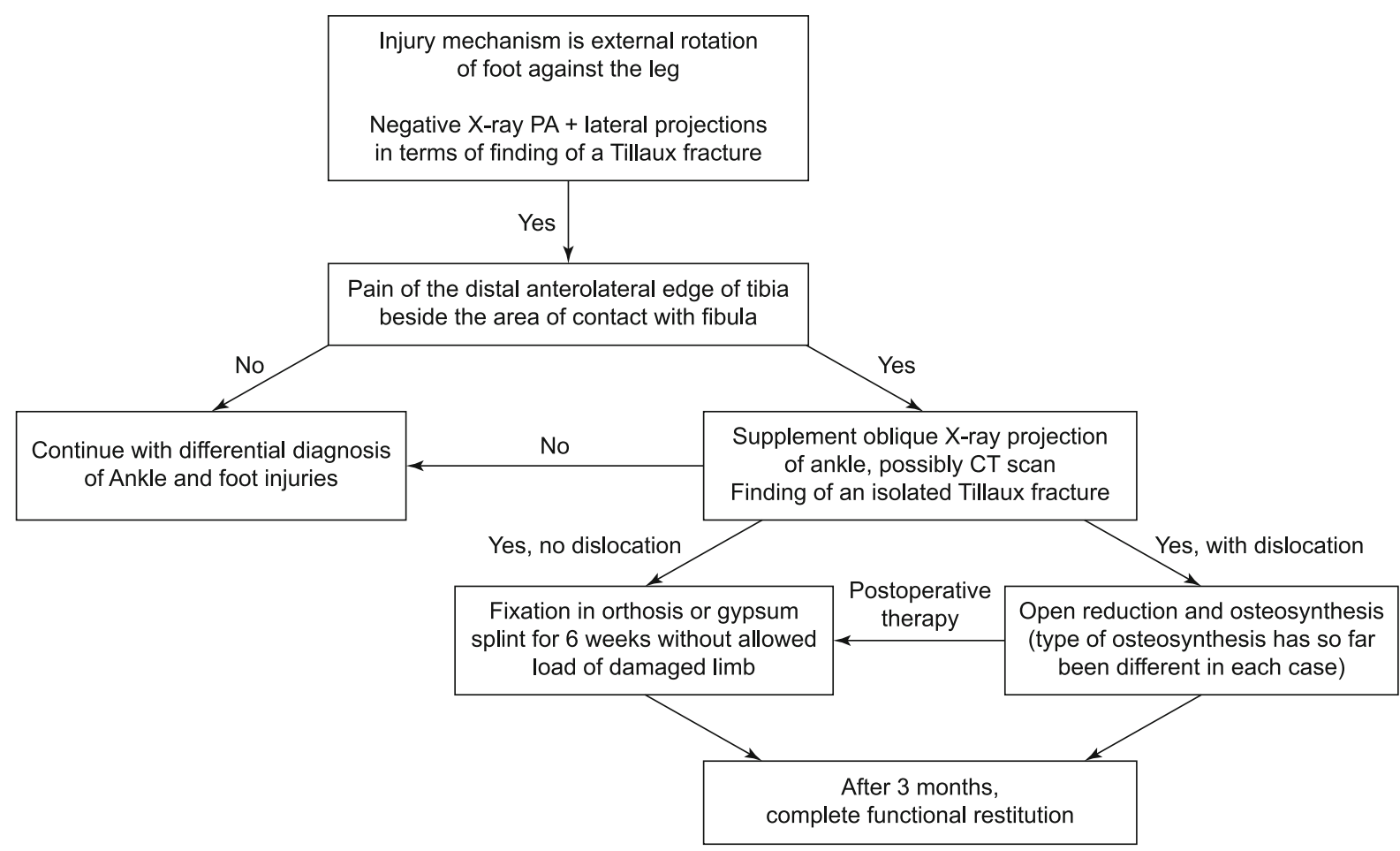

Scheme 1. Algorithm of diagnosis and treatment.

appropriate. The critical point was that an early diagnosis played a significant role in a successful treatment and recovery (8). Conservative treatment consisted in the mentioned cases of fixation for six weeks, by long leg cast with the internally rotated foot (13) without allowed load of the injured limb. Surgical treatment of the mentioned cases was matched in the choice of open position, but was differentiated in the types of fixation and osteo-material selection. Also, post-operative treatment, type, and duration of fixation were variable. In almost all the cases, full functioning returned within three months, and the gait was not biomechanically damaged. Based on the mentioned case studies, we developed an algorithm for diagnosis and treatment (Scheme 1). According to our experiences in the last ten years, we faced adult Tillaux fracture in a single case. According to literature, we found 23 published cases from 2006 to the present day. Besides its rarity, the adult Tillaux fracture can cause severe short and long-term complications, which can lead even to conditions such as incapacity for work or deterioration in the quality of life. On the other hand, well diagnosed and treated patient has a high chance to get fully recovered back to his/her job, activities and everyday life. That is why we consider that our algorithm could be a useful tool to ease the process of diagnostics and treatment and be another little step in improving healthcare within the foot and ankle injuries (Scheme 1).

\section{Discussion}

Isolated Tillaux fracture in adults is very rare and can be easily overlooked. According to some studies, it is classified as an analogue to Von Laer L biplane and triplane fracture, specifically to biplane fracture of the epiphysis (14). There is not a consensus regarding its exact term. Its diagnosis may be treacherous and may escape the eyes of experienced radiologists, traumatologists, or orthopaedists. The clinical picture of the Tillaux fracture is usually presented by tenderness and swelling in the region of the anterolateral distal border of the tibia, with mobility usually not limited. In case of suspicion of this fracture based on clinical examination, even in the case of negative PA and lateral X-ray images, it is advisable to complement the diagnostic procedure with an oblique projection. In order to exclude damage of syndesmosis in case of clinical suspicion, it is advisable to add a stress $\mathrm{X}$-ray or MR examination. Computed tomography can be a useful adjunct to confirm the diagnosis, clearly define the extent of the fracture, and rule out any associated injuries involving the tibial pilon (15).

When choosing a treatment, it is recommended for conservative treatment if the fragment dislocation size does not exceed $2 \mathrm{~mm}$ (9) (16). As the anteroinferior ligament is attached to the fibula, it causes displacement and angulation of the fragment (17). Fracture pattern could be clearly defined preoperatively (12). If the fracture is displaced, more than $2 \mathrm{~mm}$ closed reduction without an internal fixation may fail because of the interposition of bony fragments, periosteum or soft tissue between the fracture fragment and tibia (18). Surgical treatment, open/closed reduction (or even arthroscopically assisted), and osteosynthesis are recommended for pronounced dislocations (19). The most appropriate type of osteosynthesis is still difficult to conclude, but it is conditioned 
mainly by fragmentation of the fractures. For a monofragmented fracture type, it should suffice with a screw, whereas in the multifragmentary fracture, the plate is more appropriate. It is also not yet clear whether the fibula should be temporarily fixed to the tibia. Irrespective of the type of treatment, fixation for six weeks without permission to load the injured limb is indicated.

However, the most crucial step is to think about the diagnosis. Therefore, we considered it essential to recall this diagnosis and summarize the experience published so far. In the case of incorrect diagnosis and subsequent inappropriate treatment, we assume the risk of various complications. These may lead to the disturbing of the biomechanics of gait, or even widening of the ankle, instability, pain if treatment is late or missed (10) (12) (20). Later consequences are early arthrosis of the ankle and the associated difficulties.

\section{Conclusion}

In our study, we focused on summarizing our own and previously published cases of rare Tillaux fracture in adults and compared the characteristics of each case. The main objective was to recall the existence of this fracture and to facilitate the selection of diagnostic and therapeutic procedures with summarized information.

\section{References}

1. Duchesneau S, Fallat LM. The Tillaux fracture. J Foot Ankle Surg 1996; 35.

2. Habusta SF, Griffin EE. Tillaux fracture. In: StatPearls [online]. Treasure Island (FL): StatPearls Publishing. https://www.ncbi.nlm.nih.gov/ books/NBK482332/

3. Tillaux PJ. Traite d'anatomie topographique avec applications a la chirurgie. Paris: Hachette Livre - BNF 1892: 1148.

4. Dias LS, Giegerich CR. Fractures of the distal tibial epiphysis in adolescence. J Bone Joint Surg Am 1983; 65 (4): 438-444.

5. Vander-Griend RA, Savoie FH, Hughes JL. Fractures of the ankle. In: Rockwood CA, Green DP, Bucholz RW (Eds). Rockwood and Green's fractures in adults. Philadelphia: J.B. Lippincott Company, 1991: 1983-2040.

6. Subramanyam KN, Tammanaiah M, Mundargi AV, Bhoskar RN, Reddy PS. Outcome of complex tibial plateau fractures with Ilizarov external fixation with or without minimal internal fixation. Chin. J. Traumatol 2019; 22(3): 166-171.
7. Chase R, Usmani K, Shahi A, Graf K, Mashru R. Arthroscopic-Assisted Reduction of Tibial Plateau Fractures. Orthop. Clin. North Am 2019; 50 (3): 305-314.

8. Poyanli O, Unay K, Akan K, Ozkan K, Ugutmen E. Distal tibial epiphyseal fracture (Tillaux) and capsular interposition. J Am Podiatr Med Assoc 2009; 99: 435-437.

9. Sharma B, Reddy IS, Meanock C. The adult Tillaux fracture: one not to miss. BMJ Case Rep 2013. doi: 10.1136/bcr-2013-200105.

10. Oak NR, Sabb BJ, Kadakia AR, Irwin TA. Isolated Adult Tillaux Fracture: A Report of Two Cases. J Foot Ankle Surg 2014; 53 (4): 489-492.

11. Chokkalingam S, Roy S. Adult Tillaux Fractures Of Ankle: Case Report. The Internet Journal of Orthopaedic Surgery 2006; 6 (1). https:// print.ispub.com/api/0/ispub-article/13177.

12. Kumar N, Prasad M. Tillaux Fracture of the Ankle in an Adult: A Rare Injury. J Foot Ankle Surg 2014; 53 (6): 757-758.

13. Mishra PK, Patidar V, Singh SP. Chaput Tubercle Fracture in an Adult- A Rare Case Report. J Clin Diagn Res 2017; 11 (3). https://www. ncbi.nlm.nih.gov/pmc/articles/PMC5427393/.

14. Von Laer L. Classification, diagnosis, and treatment of transitional fractures of the distal part of the tibia. J Bone Joint Surg Am 1985; 67 (5): 687-698.

15. Horn BD, Crisci K, Krug M, Pizzutillo PD, MacEwan GD. Radiographic evaluation of juvenile Tillaux fractures of the distal tibia. J Paediatroc Orthop 2001; 21 (2): 162-164.

16. Gajdos R, Bozik M, Stranak P. Is an implant removal after dorsal plating of distal radius fracture always needed? Bratisl Med J 2015; 116 (6): 357-362.

17. Cooperman DR, Spiegel PG, Laros GS. Tibial fractures involving the ankle in children. The so-called triplane epiphyseal fracture. J Bone Joint Surg Am 1978; 60 (8): 1040-1046.

18. Simon WH, Floros R, Schoenhaus H, Jay RM. Juvenile fracture of Tillaux. A distal tibial epiphyseal fracture. J Am Podiatr Med Assoc 1989; 79 (6): 295-299.

19. Cooper AP. In: A Treatise on Dislocations and on Fractures of the joints. London: Longman, Hurst, Reese, Orme and Brown. E Cox and Son; 1822. On dislocation of the ankle joints.

20. Choudhry IK, Wall EJ, Eismann EA, Crawford AH, Wilson L. Functional outcome analysis of triplane and Tillaux fractures after closed reduction and percutaneous fixation. J Pediatr Orthop 2014; 34: 139-143.

21. Feng SM, Sun QQ, Wang AG, Li CK. “All-Inside” Arthroscopic Treatment of Tillaux-Chaput Fractures: Clinical Experience and Outcomes Analysis. J Foot Ankle Surg. 2018; 57 (1): 56-59.

Received February 2, 2020. Accepted April 6, 2020. 